\title{
SOCIAL ENVIRONMENT AND OVULATION IN THE VOLE, MICROTUS AGRESTIS
}

\author{
S. R. MILLIGAN \\ Department of Agricultural Science, University of Oxford, \\ Parks Road, Oxford OX1 3PF
}

(Received 20th September 1974)

\begin{abstract}
Summary. Although $M$. agrestis normally ovulates following coitus, virgin females in the present study ovulated when separated from a male by a single barrier of wire mesh. A smaller number ovulated when tactile contact with the male was eliminated. Changing the male behind the barrier appeared particularly effective in inducing ovulation. Control females, in the absence of males, did not ovulate. Corpora lutea resulting from the ovulations normally started to degenerate within about 3 days of their formation. Short-term changes in the vaginal smear and in sexual behaviour accompanied the ovarian changes. Direct histological evidence indicated that ovulations could be repeated once; indirect evidence (based on vaginal smears) suggested that short ovulatory cycles could occur. The significance of these results in relation to the ovulatory mechanism of the vole is discussed.
\end{abstract}

\section{INTRODUCTION}

There has been some uncertainty over the nature of the ovulatory mechanism of the short-tailed field vole, Microtus agrestis. Brambell \& Hall (1939) considered it to be a spontaneous ovulator, which in the wild exhibited one or more sterile oestrous cycles at the beginning of the breeding season or following puberty. Chitty \& Austin (1957) reported that $M$. agrestis could exhibit either a 'prolonged period of an oestrous state', during which ovulation could be induced by coitus, or 'a typical short oestrous cycle as in rats and mice' and Chitty (1957) implied that such cycles were accompanied by spontaneous ovulation. The oestrous state shown by females was thought to be determined by their social environment and history (Chitty \& Austin, 1957). Chitty (1957) also reported that the vole exhibited 3- to 4-day oestrous cycles during lactation. These studies provided no positive evidence, however, for spontaneous ovulation. Breed $(1967,1969)$ confirmed the reports of Austin (1957) and Chitty \& Austin (1957) that ovulation could be induced by coitus, and found no evidence of spontaneous ovulation in either virgin or lactating voles. Evidence for induced ovulation has been obtained in several other species of Microtus (see Bodenheimer \& Sulman, 1946; Greenwald, 1956; Richmond \& Conaway, 1969; Clulow \& Mallory, 1970; Kirkpatrick \& Valentine, 1970; Cross, 1972) and both Breed (1967) and Richmond \& Conaway (1969) have proposed that there is 
only circumstantial evidence for spontaneous ovulation in any species of the genus.

During an investigation of the possible influence of adult $M$. agrestis on the development of young females, however, corpora lutea were unexpectedly found in nine of twenty-one virgin females that had been separated from an adult male by a single barrier of wire mesh, under conditions in which mating was impossible. This observation raised again the problem of the cause of ovulation in $M$. agrestis and experiments have been performed to investigate the matter further.

\section{METHODS}

\section{Animals and general maintenance}

Laboratory bred $M$. agrestis were used in all experiments. The main breeding stock had been established in 1959 and was a closed colony until 1972. Animals from this colony, which were also used in the studies of Breed (1967, 1969), will be referred to as 'laboratory type' (LT). In 1971, a separate, subsidiary breeding colony was established, composed of animals caught in the wild and their first generation offspring. Animals from this colony will be referred to as 'wild type' (WT). In 1972, WT animals were introduced into the main breeding colony. Voles from this mixed colony will be referred to as 'mixed type' (MT). The LT and MT stock have been subject to some selection for higher fertility.

Breeding animals were normally kept in permanent heterosexual pairs. Young were weaned at 16 days of age. Males used in the experiments were fertile adults from the breeding colony. All animals were maintained on a daily regimen of $16 \mathrm{hr}$ light $/ 8 \mathrm{hr}$ dark, and were supplied with fresh carrot twice weekly and unrationed water, oats, hay and Oxoid rat/mouse breeding diet. Sawdust and non-absorbent cotton wool were provided as bedding. Food and bedding were renewed twice weekly.

\section{Experimental maintenance}

Experimental females were housed in wire-topped plastic cages of either $42 \times$ $25 \times 12 \mathrm{~cm}$ (large cages), or $29 \times 19 \times 10 \mathrm{~cm}$ (small cages). Most experiments involved the use of large cages, secured to the floor of each of which was a closed tunnel made from $0.8 \mathrm{~cm}$ wire mesh. Each tunnel could house an adult vole while the experimental females lived in the remaining space of the cage. Tunnels were either 'single', providing only a single barrier of mesh between any animal within the tunnel and animals outside, or 'double', in which two barriers of mesh, $2.5 \mathrm{~cm}$ apart, separated the inside from the outside.

Two principal experimental treatments were used. For Treatment A, the females were caged in the presence of a fertile adult male confined within a tunnel. For Treatment $\mathrm{B}$, the females were in a cage containing a tunnel, but with no male. The main conditions of each experiment are summarized in Table 1. Additional details of individual experiments will only be given where necessary. Females were allocated randomly to treatments within 2 days of weaning. The females within any one cage were of similar age, and except where otherwise stated, they were initially housed three to five per cage and maintained in their 
respective cages until killed. They were usually killed after the vaginal smears indicated that ovulation might have occurred (see below), or after a prolonged period in the experimental situation. Except in Exp. 4 and Treatment AIII of Exp. 6, animals within the tunnels were replaced weekly. All renewals were made at a time when the cages were cleaned.

The experimental cages were kept in rooms well separated from the general animal rooms. Those cages containing a WT male were housed in a different room from those with LT or MT males, Cages containing only females were kept in a room free of males, except in Exp. 3, when all treatment cages were in the same room.

Experiments 1 and 2 represent a summary of a number of subsidiary experiments, each of which involved some of the stated post-weaning conditions. The degree of the pre-weaning exposure of the experimental females to males varied in these experiments, but the results did not indicate that the preweaning conditions were of importance in determining the occurrence of ovulation. The results from these subsidiary experiments were therefore combined and considered in relation to the post-weaning conditions.

In Exp. 4, transfer of females from Treatments A and B took place only after at least 12 days had elapsed from the onset of 'vaginal cornification' (see below). Before any female was moved to Treatment A1, she was isolated for 3 days in a cage with an empty double tunnel in the experimental room containing males. Corpora lutea and smear changes associated with ovulations in Treatment Al could therefore potentially be easily distinguished from any associated with those in either of the earlier treatments. In Treatments Al and B1, the females were caged singly. Males were renewed twice weekly in Treatment A and Al of this experiment.

\section{Vaginal smears}

Females were examined daily for vaginal perforation, after which vaginal smears were taken daily at 08.00 to 09.30 hours. Both these procedures were performed twice daily in Exp. 6. Vaginal smears were taken with a wire loop and stained with Toluidine blue. The abundance of leucocytes, nucleated epithelial and cornified cells was assessed for each smear. Smears with few cells were classified as 'thin'.

\section{Mating tests}

Many females were tested for sexual receptivity immediately before autopsy. A male was placed in a small, clean cage $5 \mathrm{~min}$ before the introduction of the female. The pair was left for $1 \mathrm{hr}$ and the female was then examined for evidence of mating (the presence of either a copulatory plug or of spermatozoa in the vagina). A test was regarded as successful if mating occurred. Most females were killed on completion of the test, but some were killed after a further $12 \mathrm{hr}$ isolation to determine whether the mating had induced ovulation (Breed \& Clarke, 1970a). In the following account, those ovulations and corpora lutea which are not specifically stated to be associated with a mating test were not induced by coitus. Such ovulations will be described as 'non-coitallyinduced'. 


\section{Ovarian histology}

All ovaries were fixed in Bouin's fluid, embedded in paraffin wax, serially sectioned at $7 \mu \mathrm{m}$ and stained with Ehrlich's haematoxylin and eosin. The diameter of each corpus luteum (CL) and Graafian follicle was taken as the mean of two measurements at right angles through their largest section. Histologically healthy follicles over $400 \mu \mathrm{m}$ in diameter were classified as Graafian follicles (see Breed, 1969). Luteinized structures containing ova were not classified as CL.

Table 1. Individual experimental conditions and occurrence of ovulations in the vole

\begin{tabular}{|c|c|c|c|c|c|c|}
\hline $\begin{array}{l}\text { Exp. } \\
\text { no. }\end{array}$ & $\begin{array}{l}\text { Genotype } \\
\text { of } \\
\text { females }\end{array}$ & Treatment of females & $\begin{array}{c}\text { Total } \\
\text { no. of } \\
\text { females }\end{array}$ & $\begin{array}{l}\text { No. showing } \\
\text { vaginal } \\
\text { cornification }\end{array}$ & $\begin{array}{l}\text { No. } \\
\text { killed } \dagger\end{array}$ & $\begin{array}{l}\text { No. with } \\
\quad C L\end{array}$ \\
\hline 1 & $\begin{array}{l}\text { LT } \\
\text { and/or } \\
\text { MT }\end{array}$ & $\begin{array}{l}\text { A. Single tunnel with LT male } \\
\text { A. Single tunnel with MT male } \\
\text { A. Single tunnel with WT male } \\
\text { B. Single tunnel with no animal } \\
\text { B. Single tunnel with MT female }\end{array}$ & $\begin{array}{r}11 \\
15 \\
5 \\
8 \\
8\end{array}$ & $\begin{array}{r}11 \\
13 \\
4 \\
6 \\
7\end{array}$ & $\begin{array}{r}9 \\
12 \\
3 \\
4 \\
5\end{array}$ & $\begin{array}{r}9 \\
10 \\
2 \\
0 \\
0\end{array}$ \\
\hline 2 & WT & $\begin{array}{l}\text { A. Single tunnel with WT male } \\
\text { A. Single tunnel with LT male } \\
\text { B. Single tunnel with no animal }\end{array}$ & $\begin{array}{r}20 \\
8 \\
21\end{array}$ & $\begin{array}{r}18 \\
3 \\
16\end{array}$ & $\begin{array}{r}11 \\
2 \\
9\end{array}$ & $\begin{array}{l}4 \\
1 \\
0\end{array}$ \\
\hline 3 & MT & $\begin{array}{l}\text { A. Single tunnel with MT male } \\
\text { A. Double tunnel with MT male } \\
\text { B. Double tunnel with no animal }\end{array}$ & $\begin{array}{l}6 \\
7 \\
7\end{array}$ & $\begin{array}{l}4 \\
7 \\
6\end{array}$ & $\begin{array}{l}5 \\
3 \\
4\end{array}$ & $\begin{array}{l}5 \\
1 \\
0\end{array}$ \\
\hline 4 & MT & $\begin{array}{l}\text { A. MT male in single tunnel, followed } \\
\text { by AI, MT male in double tunnel } \\
\text { B. No animal in single tunnel followed }\end{array}$ & 7 & 7 & 3 & 2 \\
\hline \multirow{4}{*}{6} & \multirow{4}{*}{$\begin{array}{l}\text { MT } \\
\text { MT }\end{array}$} & $\begin{array}{l}\text { by AI, MT male in double tunnel } \\
\text { AT male in single tunnel, followed } \\
\text { by B, no animal in double tunnel }\end{array}$ & $\begin{array}{l}8 \\
8\end{array}$ & $\begin{array}{l}8 \\
8\end{array}$ & $\begin{array}{l}2 \\
2\end{array}$ & $\begin{array}{l}1 \\
0\end{array}$ \\
\hline & & $\begin{array}{l}\text { Females isolated, or in single litter } \\
\text { groups. No males or tunnels }\end{array}$ & 14 & 14 & 8 & 0 \\
\hline & & $\begin{array}{l}\text { AII. Single tunnel with MT male } \\
\text { renewed weekly }\end{array}$ & 6 & 6 & $4^{*}$ & 4 \\
\hline & & $\begin{array}{l}\text { renewed infrequently } \\
\text { B. Single tunnel with no animal }\end{array}$ & $\begin{array}{l}6 \\
6\end{array}$ & $\begin{array}{l}5 \\
6\end{array}$ & $\begin{array}{l}4^{*} \\
2\end{array}$ & $\begin{array}{l}4 \\
0\end{array}$ \\
\hline
\end{tabular}

For abbreviations, see text.

* Including animals killed following a 'Jong' dioestrous period (see text).

$\uparrow$ During the 6 days after the onset of a dioestrous period.

\section{RESULTS}

\section{Vaginal smear patterns}

A basic pattern of vaginal smears was common to most females. Following vaginal perforation, few cornified cells were present, but leucocytes and small round nucleated cells were common. Later, cornified and nucleated epithelial cells became abundant, while leucocytes were rare. Characteristically, there was then a long period of predominantly cornified smears, with occasional interruptions by short periods of leucocytic and/or thin smears. An animal was judged to have reached the stage of 'cornification' when it exhibited the third consecutive cornified smear. Once a female had reached cornification, subsequent reversion to long periods of leucocytic and/or thin smears was rare. 
These observations confirm and extend those of Austin (1957) and Chitty \& Austin (1957).

Initial results from Exp. 1 indicated that each non-coitally-induced ovulation could invariably be associated with an interruption of a sequence of cornified smears by a short period of leucocytic and/or thin smears. They were treated only as indicators of the possible occurrence of ovulation, however, since some interruptions also occurred unassociated with ovulation. These interruptions will be referred to as 'dioestrous periods'. Nucleated epithelial cells were often particularly common in the smear immediately preceding and/or following each dioestrous period. The duration of each period was taken from the time of its appearance (Day 0 ) to the occurrence of the first cornified or nucleated epithelial cell smear following the period. The interval between successive dioestrous periods was taken as the interval between the initiation of those periods.

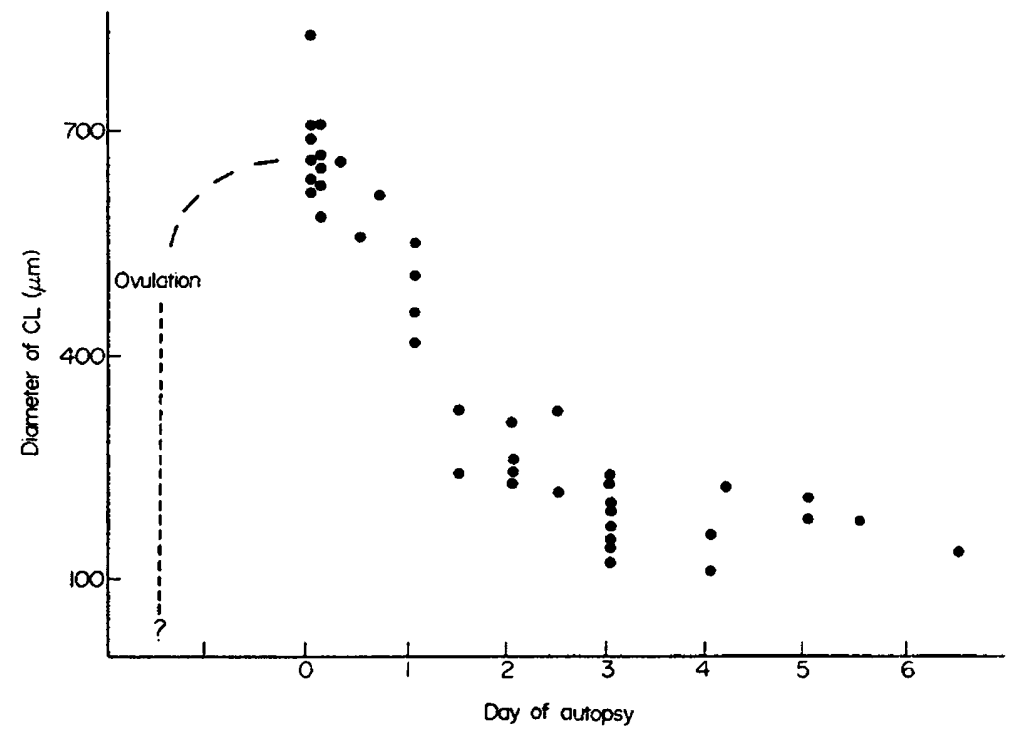

TExT-PIG. 1. Mean diameter of each generation of CL in relation to the time of death of each female. Day 0 represents the day of onset of the dioestrous period associated with the GL.

\section{Experiments 1 to 5}

Influence of genotype and social environment on ovulation. The results are summarized in Table 1. Corpora lutea were found in some females in all the treatments that involved separating the females from a male by a single or a double wire mesh barrier. No CL were found in any female in treatments not involving a male. Ovulation was far less common in females separated from the male by a double, rather than a single barrier (Exp. 3). The single ovulation observed in this experiment when the male was behind the double barrier could not be attributed with any confidence solely to an effect of the male. However, three of four other females (not included in Table 1), previously caged in the presence of a male confined within a single tunnel, ovulated when isolated and exposed to a male behind a double barrier. While this result showed that the presence of a 
male behind a double barrier was sufficient to result in ovulation, it also raised the possibility that the previous exposure of the females to a male behind a single barrier might have accentuated the ovulatory response of the females in the double-barrier situation. Experiment 4 was designed to test this possibility, but no evidence was obtained for any significant accentuation.

Correlation of ovarian events with the vaginal smear pattern. Almost all females in which CL had been found had reached the stage of cornification before the appearance of the dioestrous period that was associated with the CL; the three exceptions had each shown two consecutive cornified smears preceding the associated smear change. The duration of completed dioestrous periods associated with ovulation varied between 1 and 3 days, with a median duration of 1 day.

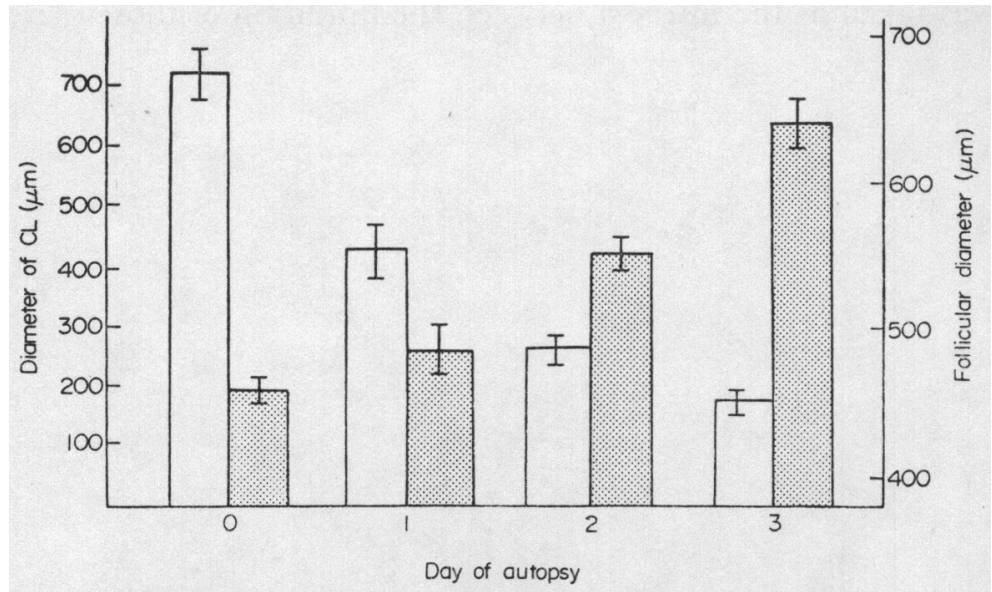

TeXT-FIG. 2. Mean diameter ( \pm S.E.) of Graafian follicles (stippled columns) and most recent generation of GL (open columns) in relation to time of autopsy of females after the onset (Day 0 ) of a dioestrous period. Data from three animals killed on each day.

For each generation of CL that could be associated with a dioestrous period, a close relationship was observed between the size and histology of the CL and the time elapsing between the onset of the period and death (Text-fig. 1). In four voles, CL could not be associated with a dioestrous period and these CL were histologically similar to those normally found within about $24 \mathrm{hr}$ of mating (Breed \& Clarke, 1970a). The CL of females killed on the morning of Day 0 were observed to be similar to those of mated females at about 2 days post coitum. Since ovulation normally occurs 9 to $12 \mathrm{hr}$ after an inducing stimulus (Austin, 1957; Breed \& Clarke, 1970a), these observations suggest that each dioestrous period appeared about $1 \frac{1}{2}$ days after ovulation. Females killed after Day 0 all possessed regressing CL, suggesting that the CL started to degenerate soon after their formation. Regression involved a rapid reduction in size and vascularity, an invasion of leucocytes into the CL, loss of distinction of cell boundaries, cytoplasmic vacuolation and nuclear condensation and pyknosis. These changes were similar to those following male-induced pregnancy block (Milligan, 1974).

The rapid degeneration of the CL suggested that they could not be identified 
for more than about 5 or 6 days after the appearance of the associated dioestrous period. A total of forty-three of the sixty-one periods $(71 \%)$ observed in females in a Treatment-A situation and occurring during the 6 days before autopsy, could be associated with $\mathrm{CL}$ at death. Nine females each possessed two generations of CL. In six of these animals, the associated dioestrous periods were 3 to 5 days apart, suggesting that the ovulations had occurred at similar intervals. The other three females each possessed a set of CL formed too recently before death to be associated with a smear change. None of the thirty-four dioestrous periods observed in females in Treatment-B during the 6 days before death were associated with CL.

No Graafian follicles were found in any of the females that had been killed soon after ovulation and before an associated dioestrous period had occurred. Small Graafian follicles were present on Day 0, but their size increased steadily as the CL regressed (Text-fig. 2).

A determination was made of the day of the week on which each dioestrous period (associated with ovulation) had been initiated. The daily distribution of occurrence of these periods (Text-fig. 4a) was significantly different from a uniform distribution $\left(\chi^{2}=26.6 ;\right.$ d.f. $\left.=6 ; P<0.001\right)$.

\section{Experiment 6}

Temporal occurrence of ovulations. At least some females in Exps 1 to 4 had ovulated twice within 3 to 5 days, but it was not clear whether a regular cycle of ovulations could occur. In view of the short life of the GL, an examination of ovarian histology alone could not provide any direct evidence for such a cycle. The relationship between ovulations and dioestrous periods, however, suggested that examination of vaginal smear records could provide evidence for or against the occurrence of regular ovulation.

The females in each treatment of this experiment (see Table 1) were housed in the same cage. The male in Treatment AII was renewed weekly, but in Treatment AIII the male was replaced only twice during the course of the experiment, initially when the females were 64 to 65 days of age and again at 92 to 93 days. Females were killed some weeks after the onset of cornification and often within a few days of the completion of a dioestrous period. One female in Treatment AIII died before the vagina became perforate and was excluded from the results.

Two types of dioestrous period, distinguishable by their duration (see Textfig. 3), were observed in females caged in close proximity to males (Treatments AII and AIII). The majority of the periods (fifty-six of the sixty-two completed) were less than 3 days in length, with a median duration of 1 day. Two females from each of Treatments AII and AIII were killed within 5 days of the occurrence of one of these short periods and were found to possess degenerating CL (Females 3, 5, 7 and 12). In addition, five females showed a total of six dioestrous periods of 6 to 8 days duration (median length of 7.5 days). These longer periods almost certainly reflected a pseudopregnant condition, as the smear pattern was similar to that accompanying the pseudopregnancy following sterile mating (Breed \& Clarke, 1970b) and the three individuals killed soon after the completion of such a dioestrous period possessed degenerating CL (Females 6, 8 and 9). 
Female 1 was killed 2 days after the initiation of the final dioestrous period and before its completion. Histologically healthy CL were found in this female, suggesting that this female may have been in a potentially pseudopregnant condition.
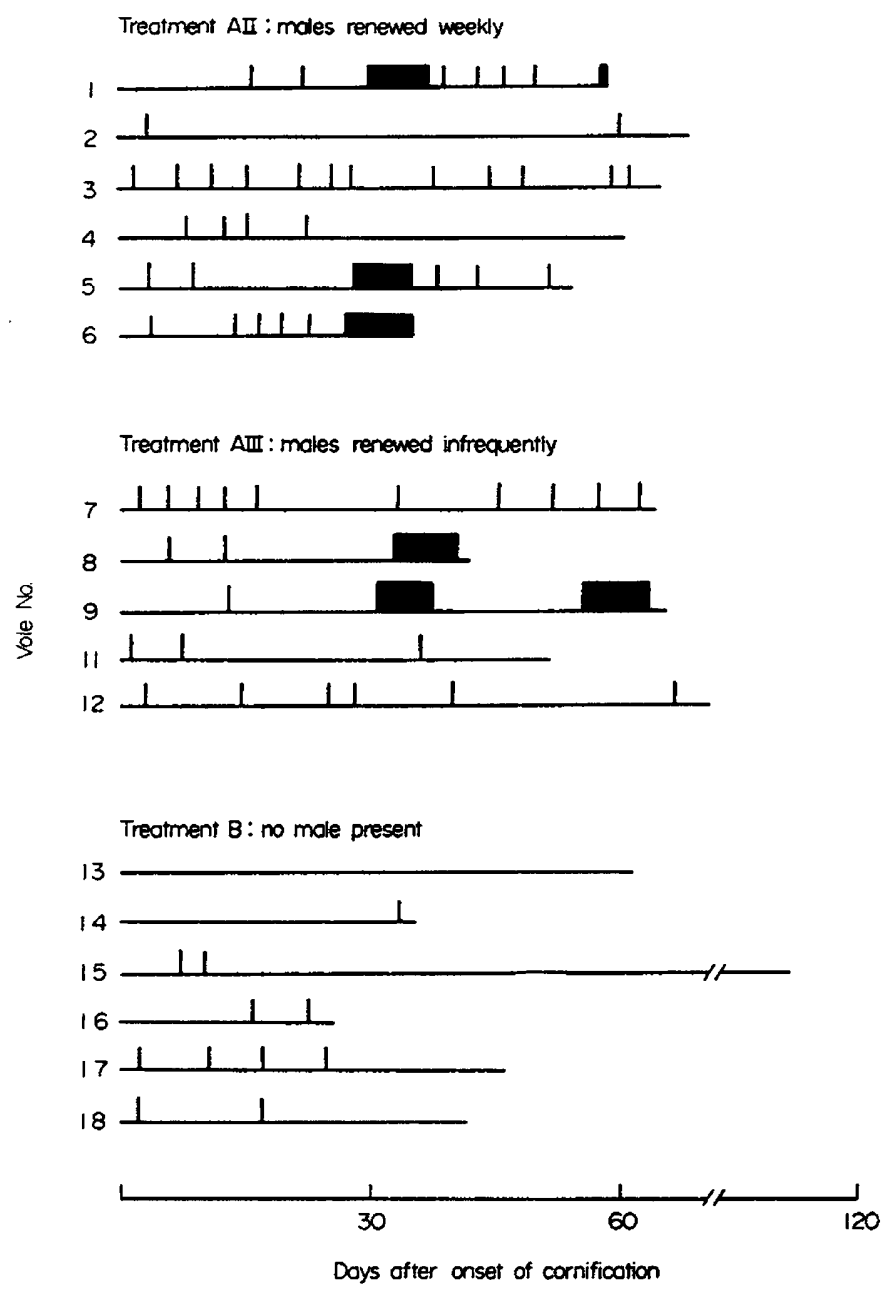

TEXT-FIG. 3. Vaginal smear records from the onset of vaginal cornification in voles in Exp. 6. Consecutive cornified and/or nucleated epithelial smears (horizontal line); dioestrous period of less than 3 days duration (vertical line); dioestrous period of 6 to 8 days duration (large solid block); incomplete dioestrous period (small solid block).

The dioestrous periods observed in the females in Treatment B were $\frac{1}{2}$ to 1 day in length; neither of the two females killed soon after a dioestrous period nor any of the other females possessed CL at death.

The interval between successive dioestrous periods (see Text-fig. 3) showed considerable variation both within and between females. However, a more or less regular succession of these interruptions of the predominantly cornified smear pattern did occur in some females, most commonly with a periodicity 
Ovulation in Microtus agrestis

Table 2. Regular sequences of dioestrous periods found in voles in Experiment 6

\begin{tabular}{c|c|c|l}
\hline Treatment & $\begin{array}{c}\text { Female } \\
\text { No. }\end{array}$ & $\begin{array}{c}\text { No. of } \\
\text { dioestrous } \\
\text { periods }\end{array}$ & \multicolumn{1}{|c}{ Intervals (days) } \\
\hline AII & 1 & 3 & 6,8 \\
& 3 & 4 & $4 \frac{1}{2}, 3 \frac{1}{2}, 3 \frac{1}{2}$ \\
& 4 & 3 & $5,4 \frac{1}{2}, 4 \frac{1}{2}, 6,4,3$ \\
& 6 & 4 & $\frac{41}{2}, 3 \frac{1}{2}, 3 \frac{1}{2}, 3 \frac{1}{2}$ \\
AIII & 7 & 5 & $3 \frac{1}{2}, 3 \frac{1}{2}, 3 \frac{1}{2}, 4$ \\
& 12 & 4 & $6 \frac{1}{6}, 5 \frac{1}{2}, 4 \frac{1}{2}$ \\
B & 17 & 4 & $11 \frac{1}{2}, 10$ \\
& 17 & $7 \frac{1}{2}, 7,7 \frac{1}{2}$ \\
\hline
\end{tabular}

Sequences were recorded only when successive intervals did not differ by $>2$ days.

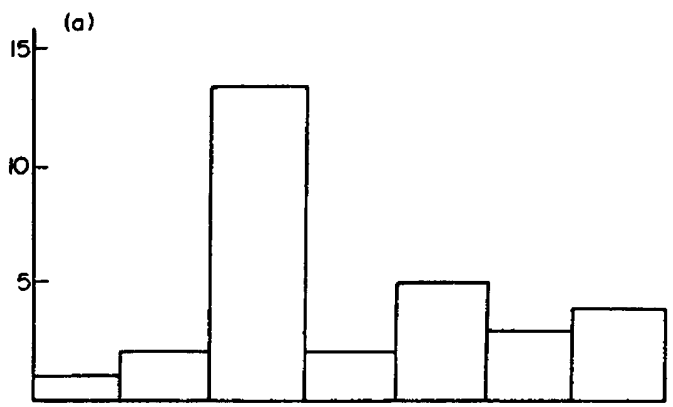

(b)

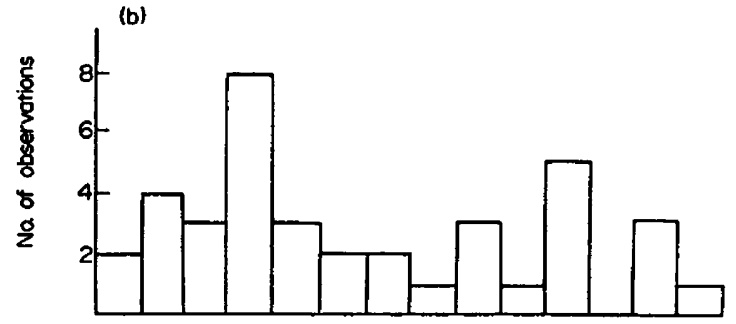

(c)

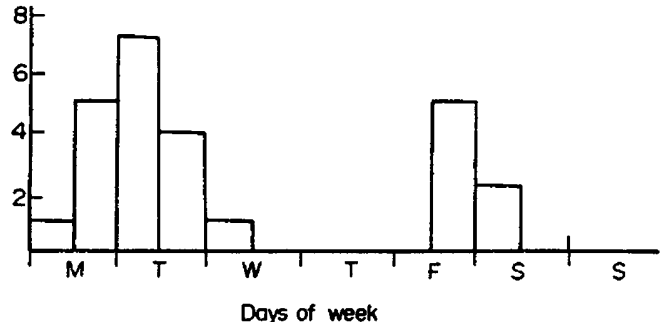

TEXT-FIG. 4. Distribution of onset of dioestrous periods in voles in relation to the weekly regimen. (a) Dioestrous periods associated with ovulation in Exps 1 to 3. (b) and (c) All dioestrous periods in Treatments AII and AIII (Exp. 6) respectively. In Exps 1 to 3 and Treatment AII of Exp. 6, males were renewed weekly on Monday mornings. Males were renewed infrequently in Treatment AIII. Cages were cleaned on Monday and Thursday mornings. 
of between 3 to 5 days (Table 2). The frequency distribution of occurrence of dioestrous periods on each half day of the week for Treatments AII and AIII is given in Text-figs $4 b$ and $4 c$, respectively.

\section{Mating tests}

The majority of females mated when they possessed a predominantly cornified smear; animals showing thin or leucocytic smears rarely mated. These results are in agreement with the findings of Austin (1957), Chitty \& Austin (1957) and Breed (1967).

Nine of the females which at death showed no histological evidence of noncoitally-induced ovulations had been left for $12 \mathrm{hr}$ after a successful test before being killed. These females all possessed freshly ovulated follicles indicating that the mating had induced ovulation. But many of the females given mating tests were subsequently found to have ovulated as a result of their earlier exposure to males within the tunnels. Females tested on the day of the onset of the dioestrous period associated with an earlier ovulation (Day 0 ), were generally not receptive (four females out of five failed to mate). The one female that did mate possessed freshly ovulated follicles when killed $12 \mathrm{hr}$ later. Most of the tests given after Day 0 were successful (twelve of the fourteen given on Days 1, 2 and 3) and all except one of the seven females killed $12 \mathrm{hr}$ after a successful test possessed freshly ovulated follicles at death.

\section{DISCUSSION}

These experiments showed that ovulations can occur in $M$. agrestis in the absence of mating and that the resulting CL normally begin to degenerate soon after formation. Short-term changes in the vaginal smear and sexual behaviour are associated with these ovulations, presumably reflecting relatively transient changes in steroid levels accompanying the ovarian events. The results also confirmed that coitus can induce ovulation in M. agrestis (Austin, 1957; Chitty \& Austin, 1957; Breed, 1967; Breed \& Clarke, 1970a); this effect was seen even in those females that had previously ovulated in the absence of coitus.

Irrespective of the genotype and of the pre- and post-weaning social environment of the females, ovulations only occurred when females were in close proximity to males. Ovulations were less common in experiments involving WT rather than LT and/or MT females (see Table 1, Exps 1 and 2), perhaps because of the inbreeding, selection and domestication of the LT and MT stock, the observed slower rate of sexual development of the WT females (J. R. Clarke and S. R. Milligan, unpublished observations), or some combination of these factors. The results suggest, however, that the mechanisms responsible for ovulation in the absence of mating, and for the short life-span of the resulting $\mathbf{C L}$, can be considered characteristic of female $M$. agrestis in general and not a peculiarity of the LT colony.

Whether or not the females were caged in the presence of a male, neither the technique of vaginal smearing nor mounting by other females were found to be necessary, or perhaps sufficient, to cause ovulation. External events, however, appeared to have a strong influence on the occurrence of ovulations. A peak of 
dioestrous periods associated with ovulation occurred on Wednesdays in Exps 1 to 3 (Text-fig. 4a), presumably reflecting a peak of ovulations late on Mondays. The only event with a unique association with each Monday was the change of males in the tunnels on Monday mornings. If this renewal was causally connected with the peak of ovulations, the mediating neuroendocrine mechanisms must have been initiated shortly after this event. These ovulations would therefore appear to have been directly induced by remote (i.e. other than coital) stimuli associated with male renewal. Other observations indicated that as little as $4 \mathrm{hr}$ exposure of females to a male within a single tunnel was sufficient to cause ovulation. In addition, although ovulations were less common when the male was behind a double barrier (Exps 3 and 4), all but one of the seven ovulations ever observed in females in this situation appeared to have occurred later on the same day as the male was introduced or renewed. This suggests that these ovulations were also directly, but remotely, induced. The results from the double tunnel situation also indicate that tactile contact between the male and female was not necessary for ovulations to occur. Pheromones are known to influence a number of aspects of reproduction in rodents (Bronson, 1971) and they may also have been important in the present experiments. The nature of the effective stimuli provided by the male is under investigation.

The results from Exp. 6 suggest that ovulatory cycles probably occurred in some females. There was no direct evidence of any association with ovulation for the majority of dioestrous periods in this experiment, but it seems likely that the correlations between social environment and ovulation, and between dioestrous periods and ovulation, were similar to those found in Exps 1 to 5. All the females killed soon after a dioestrous period in Treatments AII and AIII (i.e. with a male), possessed CL; no GL were found in any female in Treatment $B$ (without a male). The higher frequency of dioestrous periods in Treatments AII and AIII, as compared with Treatment B (see Text-fig. 3), is consistent with the view that repeated ovulations occurred in the former two treatments. The large number of short dioestrous periods in these two treatments suggests that most ovulations gave rise to short-lived CL. It seems probable that the fairly regular sequence of dioestrous periods seen in some females may have reflected cycles of ovulations. The peak of dioestrous periods observed on Tuesday evenings in voles in Treatment AII (Text-fig. 4b) suggests that the weekly change of males may have induced ovulations in these females. However, the distinct bimodal distribution of dioestrous periods in Treatment AIII (Text-fig. $4 c$ ), in which the males had been renewed very infrequently, suggests that other events, possibly occurring on a twice-weekly basis, may have influenced ovulation. General disturbances have been implicated in a number of reproductive phenomena (Richmond \& Conaway, 1969), including the induction of ovulation in persistent oestrous rats (Brown-Grant, Davidson \& Greig, 1973); such stimuli, in particular the twice weekly cage cleaning, may have been important in the present study.

The report of Chitty \& Austin (1957) of a regular 3- to 4-day cycle of vaginal smear patterns and oestrous behaviour in some $M$. agrestis would be consistent with the occurrence of regular ovulations associated with the short-lived CL. However, no direct evidence for such ovulations was obtained in their study. 
'Oestrous cycles' occurred only in females caged singly or in single litter groups, but neither the present study, nor that of Breed (1967), found any evidence of ovulation under these conditions. It is possible that those females exhibiting 'oestrous cycles' in the experiments of Chitty \& Austin may have been housed sufficiently close to males to cause ovulation; the exposure of their females to males during the tests of sexual receptivity may also have been important in this respect.

The short life of the majority of CL in the present study is in marked contrast to that of the CL normally associated with coitus-induced ovulation which remain histologically healthy for the 20 to 21 days of pregnancy or the 8 to 9 days of pseudopregnancy (Breed \& Clarke, 1970b). There was no evidence that this short life-span was associated with an inadequate ovulatory stimulus. In Exps 1 to 4 the mean number ( \pm S.E.) of non-coitally-induced CL was 4.77 $( \pm 0 \cdot 25)$. This is very similar to the number of CL observed after coitusinduced ovulation (Breed \& Clarke, 1970b).

The failure of CL accompanying 'pregnancy block' may account for the reports of 'sterile cycles' in Clethrionomys glareolus and $M$. argrestis (see Clarke \& Clulow, 1973). Gould the short life of the CL in the present study have been the result of a similar phenomenon? Five females, previously housed in the Treatment-A situation, were separately paired for $1 \mathrm{hr}$ with the male hitherto confined in the single tunnel in their cage. After the mating period, both members each pair were returned to their normal positions within the treatment cage. Four females became pregnant as a result of the mating, providing no evidence for any significant pregnancy-blocking effect. In any case, the only obvious factor that might have produced such an effect was the replacement of the males by new, and therefore 'strange', males. However, in view of the distribution of ovulations within the 'week' (inferred from Text-fig. 4a) and the rapid degeneration of the $\mathbf{C L}$, the weekly change of males could not have had any influence in limiting the life of the CL in most of the voles in Exps 1 to 3 .

A natural category of short-lived ' $\mathrm{CL}$ of ovulation' would therefore appear to exist in $M$. agrestis. Such CL presumably reflect a dissociation of the ovulatory and the luteotrophic mechanisms, both of which are normally initiated following unrestricted coitus. It has recently been found that while only minimal coital stimuli can induce ovulation in the vole, more prolonged stimulation is normally necessary to stimulate the development of luteal function (Milligan, 1975). Therefore, although the overt ovulatory control mechanism of $M$. agrestis differs from that of spontaneously ovulating species such as the rat, mouse and hamster, these species are similar in possessing the ability to separate ovulation from luteal maintenance and the capacity for coitus to stimulate luteal function. These observations again emphasise that the distinction between induced and spontaneous ovulators may be 'more one of degree than of kind' (Eckstein \& Zuckerman, 1955).

\section{ACKNOWLEDGMENTS}

I am especially grateful to $\operatorname{Dr} \mathrm{J}$. R. Clarke for his invaluable encouragements and supervision of this work, to Professor J. H. Burnett for providing facilities for this work, and to Miss Judith Tompkins for maintaining the animal colonies. 
This work was carried out during the tenure of a postgraduate studentship from the Science Research Council.

\section{REFERENGES}

Austin, C. R. (1957) Oestrus and ovulation in the field vole (Microtus agrestis). F. Endocr. 15, iv.

Bodenheimer, F. S. \& Sulman, F. (1946) The oestrous cycle of Microtus guentheri D. and A. and its ecological implications. Ecology, 27, 255.

Brambell, F. W. R. \& Hall, K. (1939) Reproduction in the field vole Microtus agrestis hirtus Bellamy. Proc. zool. Soc. Lond. 109, 133.

BREED, W. G. (1967) Ovulation in the genus Microtus. Nature, Lond. 214, 826.

BREED, W. G. (1969) Oestrus and ovarian histology in the lactating vole (Microtus agrestis). F. Reprod. Fert. 18, 33.

BreEd, W. G. \& GLARKe, J. R. (1970a) Ovulation and associated histological changes in the ovary following coitus in the vole (Microtus agrestis). F. Reprod. Fert. 22, 173.

BREED, W. G. \& Glarke, J. R. (1970b) Ovarian changes during pregnancy and pseudopregnancy in the vole, Microtus agrestis. F. Reprod. Fert. 23, 447.

Bronson, F. H. (1971) Rodent pheromones. Biol. Reprod. 4, 344.

Brown-Grant, K., Davidson, J. M. \& Greig, F. (1973) Induced ovulation in albino rats exposed to constant light. F. Endocr. 57, 7.

Chiтty, H. (1957) The oestrous cycle and gestation period in the lactating field vole, Microtus agrestis. F. Endocr. 15, 279.

Giritty, H. \& Austin, C. R. (1957) Environmental modification of oestrus in the vole. Nature, Lond. 179, 592.

Glarke, J. R. \& Clulow, F. V. (1973) The effect of successive matings upon bank vole (Clethrionomys glareolus) and vole (Microtus agrestis) ovaries. In The Development and Maturation of the Ovary and its Functions. Ed. H. Peters. Int. Congr. Ser. No. 267. Excerpta Medica, Amsterdam.

Glulow, F. V. \& Mallory, F. F. (1970) Oestrus and induced ovulation in the meadow vole, Microtus pennsylvanicus. F. Reprod. Fert. 23, 341.

GRoss, P. G. (1972) Observations on the induction of ovulation in Microtus montanus. F. Mammal. 53, 210.

Eckstein, P. \& ZuCKerman, S. (1955) Reproduction in mammals. In Comparative Physiology of Reproduction and Effects of Sex Hormones in Vertebrates. Mem. Soc. Endocr. No. 4. Eds. I. Chester Jones and P. Eckstein. Cambridge University Press, London.

Greenwald, G.S. (1956) The reproductive cycle of the field mouse, Microtus californicus. F. Mammal. 37, 213.

KiRKPatrick, R. L. \& Valentine, G. L. (1970) Reproduction in captive pine voles, Microtus pinetorum. F. Mammal. 51, 779.

MirLIGAN, S. R. (1974) Some aspects of reproduction in female mammals. D.Phil. thesis, University of Oxford.

Mrliggan, S. R. (1975) Mating, ovulation and corpus luteum function in the vole, Microtus agrestis. F. Reprod. Fert. (in press).

Richmond, M. \& Conaway, G. H. (1969) Induced ovulation and oestrus in Microtus ochrogaster. $\mathcal{F}$. Reprod. Fert., Suppl. 6, 357. 